\begin{tabular}{|c|c|c|c|c|c|c|}
\hline \multirow{4}{*}{ Impact Factor: } & ISRA (India) & $=4.971$ & SIS (USA) & $=0.912$ & ICV (Poland) & $=6.630$ \\
\hline & ISI (Dubai, UAE & $=0.829$ & РИНЦ (Russia & $=0.126$ & PIF (India) & $=1.940$ \\
\hline & GIF (Australia) & $=0.564$ & ESJI (KZ) & $=8.716$ & IBI (India) & $=4.260$ \\
\hline & JIF & $=1.500$ & SJIF (Morocco & $=5.667$ & OAJI (USA) & $=0.350$ \\
\hline
\end{tabular}

\section{SOI: $1.1 /$ TAS $\quad$ DOI: $10.15863 /$ TAS \\ International Scientific Journal Theoretical \& Applied Science}

p-ISSN: 2308-4944 (print) e-ISSN: 2409-0085 (online)

Year: $2020 \quad$ Issue: 03 Volume: 83

Published: $30.03 .2020 \quad$ http://T-Science.org
QR - Issue

QR - Article
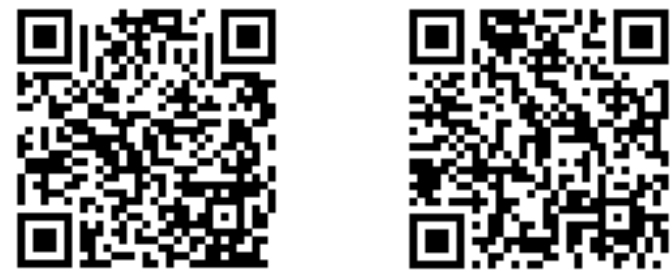

Makhmudzhon Adhamovich Davidov Ferghana State University Senior Lecturer, Candidate of Biological Sciences, mdavidov@mail.ru

Khondamir Rustamjon ugli Rustamov Ferghana State University Student of the Faculty of Natural Sciences

Muhammadali Mamirjon ugli Umarov Ferghana State University Student of the Faculty of Natural Sciences

\title{
ABOUT SOME POPULATIONS OF FERULA LIPSKYI KOROVIN (APIACEAE) FOUND IN THE FERGHANA VALLEY
}

Abstract: This article was the first to reveal new populations of the plant Ferula lipskyi Korovin in the territories of the Ferghana Region, in the steppes Okbulol, Zilol and Damkul. In the study of three populations with the participation of F.lipskyi Korovin, similarities and differences were studied, and geographical location, different soil composition, prevalence on the earth's surface, layering, and density of these populations were described. Based on the data obtained during field studies of populations, average morphometric parameters were obtained, and the number of plants in the juvenile and senile period in the populations of F.lipskyi Korovin was calculated.

Key words: population, range, juvenile, vegetative, generative, senile, morphometric parameters, Ferghana steppes.

Language: Russian

Citation: Davidov, M. A., Rustamov, K. R., \& Umarov, M. M. (2020). About some populations of Ferula Lipskyi Korovin (apiaceae) found in the Ferghana valley. ISJ Theoretical \& Applied Science, 03 (83), $262-268$.

Soi: http://s-o-i.org/1.1/TAS-03-83-50 Doi: crossef https://dx.doi.org/10.15863/TAS.2020.03.83.50

Scopus ASCC: 1101.

\section{О НЕКОТОРЫХ ПОПУЛЯЦИЯХ FЕRULA LIPSKYI KOROVIN (APIACEAE) ВСТРЕЧАЮЩИХСЯ В ФЕРГАНСКОЙ ДОЛИНЕ}

Аннотация: В данной статье, были впервые выявлены новые популяции растения Ferula lipskyi Korovin на территориях Ферганской области, в степях Окбулол,Зилол и Дамкул. При изучениитрех популяции с участиемF.lipskyi Korovin были изучены сходства и различия, а также описаны географическое положение, различный состав почвы, уровень распространённости на земной поверхности, ярусность,плотность данных популящий. На основе данных,полученных во время полевых исследований популячий, были получены средние морфометрические параметры,а также подсчитано количество растений в ювенильном, вегетативном, генеративном и сенильном периоде в популяциях F.lipskyi Korov.

Ключевые слова: популяция, ареал, ювенильный, вегетативный, генеративный, сенильный, морфометрические параметры, Ферганские степи.

Введение

В настоящее время, важное место занимают разработка научных основ - комплексное изучение флоры Республики Узбекистан, выявление ресурсов лекарственных растений и их рациональное использование, определение 


\begin{tabular}{|c|c|c|c|c|c|c|}
\hline \multirow{4}{*}{ Impact Factor: } & ISRA (India) & $=4.971$ & SIS (USA) & $=0.912$ & ICV (Poland) & $=6.630$ \\
\hline & ISI (Dubai, UAE & $=0.829$ & РИНЦ (Russia & $=0.126$ & PIF (India) & $=1.940$ \\
\hline & GIF (Australia) & $=0.564$ & ESJI (KZ) & $=8.716$ & IBI (India) & $=4.260$ \\
\hline & JIF & $=1.500$ & SJIF (Morocce & $=5.667$ & OAJI (USA) & $=0.350$ \\
\hline
\end{tabular}

отдельных ботанических объектов имеющие важное значение,разработкатеоретических основ, интродукция и акклиматизация видов растений которые имеют перспективное и экономическое значение, создание банка генетических данных, сохранение редких и эндемичных видов растительного мира,ведение государственного кадастра.Сохранение и всестороннее изучение редких и эндемичных видов представителей растительного мира, а также разработка научных основ создания и ведения государственного кадастра является одним из перспективных направлений.

В особенности, указывает на необходимость разработки мер по сохранению и защите, а также изучение тех редких видов растений, которые сохранились в регионах с высокой плотностью населения, занимающих небольшой ареал распространения. Одним из таких видов является Ferula lipskyi Korovin. Этот вид произрастает в населённых пунктах, небольшими популяциями в Ферганской долине. Это показывает на необходимость исследований изучения во всех отношениях малораспространённых видов в ареале и разработка особых мер и мероприятий по их сохранению, вместе с тем изучение динамики популяций и исследование по научному обоснованию.

\section{Методы}

Существующее в Ферганской долине растениеFerula lipskyi Korovin было выявлено небольшими популяциями в Ферганской области,вблизи кишлаков Окбулол, Зилол и Дамкул. Название других видов в существующей популяции были приведены в “Определителе растений Средней Азии” [1] и международных базах данных International Plants Names Index [2] и The Plant List [3]. Авторы таксонов,которые были использованы в данной статье“Brummit R.K., Powell C.E. Authors of Plant Names"[4].A также , была создана карта, показывающая распространение Ferula lipskyi Korovin, в основном используя образцы из Национального гербарийного фонда (TASH) Узбекистана. В определении координатных точек было использовано приложение Google Earth, карты,которые показывают распространение ГАТ ArcMap.10 [5].Полевые исследования основаны на работах А.В. Щербакова, С.Р. Майорова [6]. Основная информация о видах в основном были взяты из данных произведений “Определитель растений Средней Азии” [1], Флора СССР[7], Флора Узбекистана[8], Иллюстрированная монография рода Ferula (Tourn.) L.[9]. Онтогенез видовой популяции,основанный на классификации предложенный T.A. Работновым[10].
Для изучения плотности популяции в каждой из них закладывалось 10 пробных площадок по $100 \mathrm{~m}^{2}$. Изучение морфометрических параметров проводилось согласно методике Злобина $[11,12]$ на 20 средне-генеративных особях. Наблюдения и измерения проводились в фазе цветения, при этом учитывались следующие параметры: высота генеративного побега, cм - h; диаметр стебля, см $\mathrm{d}$; длина сложного листа, cм - Ll; ширина сложного листа, см - S1; число листьев на одном стебле, шт $\mathrm{Nl}$; длина соцветия, см - Li.Статический анализ проведен в MSExcel 2007 с использованием стандартных показателей, рассчитаны средние арифметические значения и стандартное отклонение среднего.

\section{Полученные результаты и их анализ}

Изучение эндемических,редких и малораспространённых в ареале растений и растений, занесённых в красную книгу Республики Узбекистан, их защита и принятие необходимых мер и способов по их сохранению, в то же время изучение динамики популяции, исследование видов, производятся в основном в районах подверженных воздействию антропогенных факторов. Всё вышеперечисленное является одним из важнейших задач. Эти виды часто встречаются во флоре Ферганской долины и к ним относятся: Dorema microcarpum Korovin., Oenanthe fedtschenkoana Koso-Pol., Delphinium knorringianum B.Fedtsch., Physochlaina alica Korotk ex Kovalevsk., Fumariola turkestanica Korsh., Hedysarum gypsaceum Korotkova., Euphorbia mucronulata Prokh., Anthochlamis tianschanica Iljin., Jurinea winklerii Iljin., Tulipa scharipovii Tojibaev., T. ferganica Vved. и другие. Среди них Ferula lipskyi Korovin, вид с узким диапазоном распространения и сохранившийся небольшими популяциями в районах антропогенного воздействия (данный вид используют в животноводстве, в качестве кормового растения). Данный вид относится к семейству зонтичных и в основном произрастает на альпийских, каменистых и гравийных склонах на высоте 500900 метров в Ферганском и Памиро-Алайском хребтах Западного Тянь-Шаня, является одним из эндемичных видов горной Центральной Азии. Вид, который систематически ближе к всего к этому виду- FerulaprangifoliaKorovin отличаются от Ferula lipskyi Korovinвысотой и длиной пластинок на, формой и положением листьев в стебле растений.[1].

В последние годы было проведено много исследований по химическому составу, молекулярной биологии и филогении ряда видовферулы[13,14,15,16,17,18,19,20,21,22,23].Ис следования эндемизма, размножение и распространение видов, а также ограниченный 


\begin{tabular}{|c|c|c|c|c|c|c|}
\hline \multirow{4}{*}{ Impact Factor: } & ISRA (India) & $=4.971$ & SIS (USA) & $=0.912$ & ICV (Poland) & $=6.630$ \\
\hline & ISI (Dubai, UAE & $=0.829$ & РИНЦ (Russia & $=0.126$ & PIF (India) & $=1.940$ \\
\hline & GIF (Australia) & $=0.564$ & ESJI (KZ) & $=8.716$ & IBI (India) & $=4.260$ \\
\hline & JIF & $=1.500$ & SJIF (Morocec & $=5.667$ & OAJI (USA) & $=0.350$ \\
\hline
\end{tabular}

статус современной популяции и экологии видов, присутствующих в узком ареале и подверженных влиянию внешних факторов изучаются достаточно мало. Это также частично влияет на реализацию данного исследования.

Принимая во внимание общее количество видов FerulaL., было выявлено 180-185 видов, в том числе 130 видов (100 видов эндемиков) в Центральной Азии $[1,2,3,4]$. Этот вид широко распространён в Центральной и Юго-Западной Азии, Северной Африке, на Дальнем Востоке, в Иране, Афганистане, Пакистане, Китае, Индии и Средиземноморье. Центральная Азия также признана регионом распространения $[5,6$.]. Растёт в основном на ровных, холмистых,крутых и горных склонах с песчаными, каменистыми , гравийными, мелкозернистыми и красно-серыми песчаными склонами. В Центральной Азии, включая Южную Памирскую равнину, этот вид наиболее распространён у флороценотиповшибляка и можжевельника [24].

Основная информация о видах представлена в данной “Иллюстрированная монография рода Ferula (Tourn.) L”[6].Эта монография представляет таксономию, морфологию, места распространения, значение в хозяйстве для 133 видов. По данным, приведённым в произведении «Флора Узбекистана»насчитывается 45 видов[5]. Недавние таксономические изменения, флористические и другие исследования по изучению местной флоры в Узбекистане и анализ образцов гербария, хранящихся в национальном Гербарийном фонде Узбекистана показали, что 59 видов были распространены во флоре Узбекистана.Из них 5 видов считаются эндемичными для флоры Узбекистана.Ferula lipskyi Korovin является одним из эндемичных видов Ферганской долины.

Наши исследования в окрестностях сёл Окбулол, Зилол и Дамкул Ферганской области на период 2017-2019 гг. посвящены изучению текущего состояния популяции этого вида.

Название места: Ферганская область, Ферганский район, окрестности кишлака Чимион (Зилол), N 40¹6'49.547; Е, 71³1'45.065"E (1рисунок).

Популяция расположена на западной части склона крутизной $35^{\circ}$ и в общей сложности занимает участок площадью $25000 \mathrm{~m}^{2}$ на высоте 574-589 м над уровнем моря. Травянистый покров популяции развит умеренно слабо, с выраженной трехъярусной структурой. Травостой в видовом отношении умеренно обильный с общим проективным покрытием 40-50\%. Первый ярус (более 60 см) представлен кустарником AmmodendronconollyiBoiss. Второй ярус (25-45 см) представлен Scandixpecten-VenerisL., Trichodesmaincanum (Bunge) A.DC., Haplophyllumalberti-regeliiKorovin,

Meniocuslinifolius (StephanexWilld.) DC., ArtemisiaferganensisH.Krasch.. Третий ярус (10-20 см) образован CapparisspinozaL., MarrubiumanisodonK.Koch.,

LamioumamplexicauleL., Strigosellatrichocarpa (BoissetBunge) Botsch., Minuartiameyerii (Boiss.) Bornm.,Noneacaspica (Willd.) G.Don. ArnebiaobovataBunge. Плотность популяции 4.5 экз $/ \mathrm{M}^{2}$. Плотность генеративных особей FerulaLipskyiKorovin из общего числа растений составляет $40 \%$, вегетативных - 30\%, ювенильных $-15 \%$, а сенильных $-15 \%$.

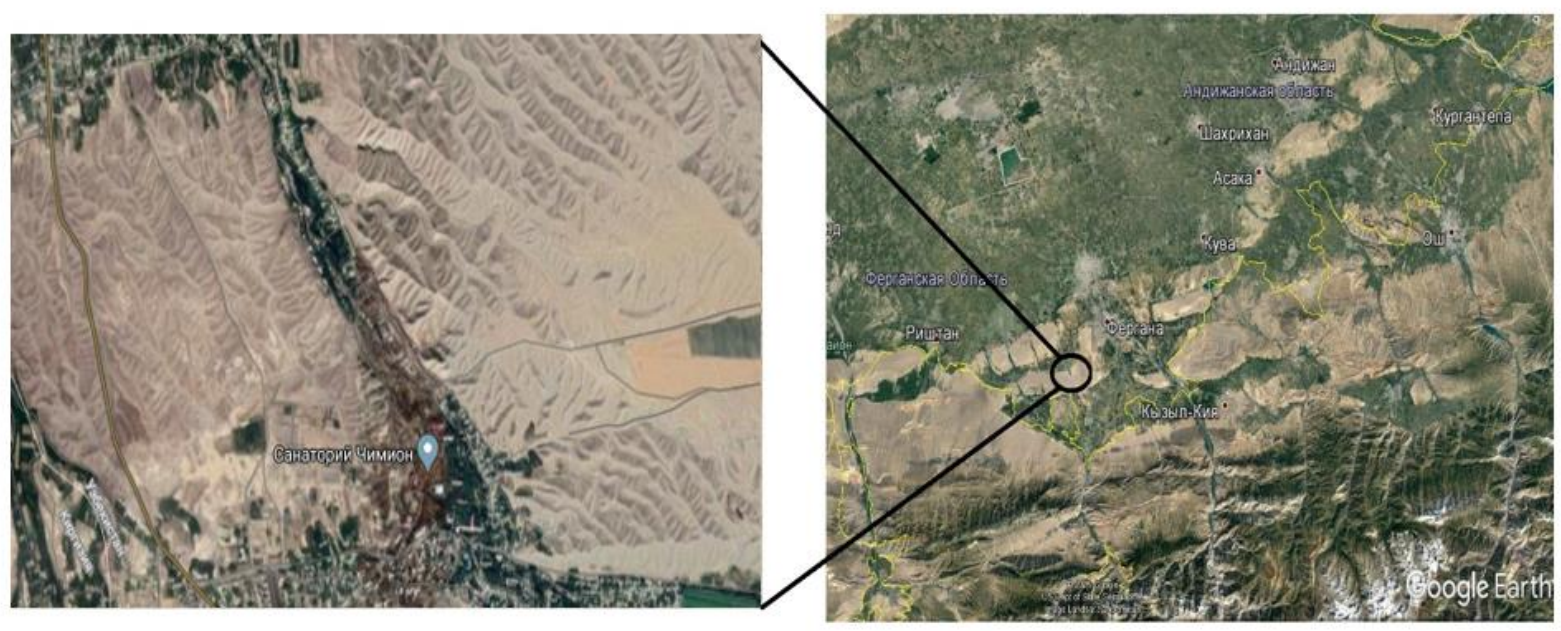

1-рисунок. Ферганский район, село Зилол.

Название места: Ферганская область, Ферганский район, село Окбилол, "N, 40¹7'45.841 Е 71²41'8.409 h=721. (2-рисунок).
Популяция расположена на западной части склона крутизной $30^{\circ}$ и занимает участок общей

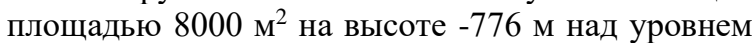
моря. Почва щебнисто-каменистая с большим 


\begin{tabular}{|c|c|c|c|c|c|c|}
\hline \multirow{4}{*}{ Impact Factor: } & ISRA (India) & $=4.971$ & SIS (USA) & $=0.912$ & ICV (Poland) & $=6.630$ \\
\hline & ISI (Dubai, UAE & $=0.829$ & РИНЦ (Russia) & $=0.126$ & PIF (India) & $=1.940$ \\
\hline & GIF (Australia) & $=0.564$ & ESJI (KZ) & $=8.716$ & IBI (India) & $=4.260$ \\
\hline & JIF & $=1500$ & SIIF (Moroces & $=5.667$ & OAJI (USA) & $=\mathbf{0 . 3 5 0}$ \\
\hline
\end{tabular}

количеством каменных валунов и отсутствием гумусного слоя почвы, характеризуется большим количеством неравномерная из-за весенних селевых потоков, смывающих поверхностную часть земли. Травянистый покров популяции развит очень слабо, с выраженной двухъярусной структурой. Травостой в видовом отношении обеднен с общим проективным покрытием 5-10\%. Первый ярус (25-45 см) представлен Scandixpecten-VenerisL., Trichodesmaincanum (Bunge) A.DC., Haplophyllumalberti-regelii Korovin, Meniocuslinifolius (StephanexWilld.)DC.. Второй ярус $(10-20 \quad$ см $)$ образован CapparisspinozaL., MarrubiumanisodonK.Koch.,
LamiumamplexicauleL., Strigosellatrichocarpa (BoissetBunge) Botsch., Minuartiameyerii (Boiss.) Bornm., Noneacaspica (Willd.) G.Don.. Плотность популяции 4.0 экз $/ \mathrm{m}^{2}$. Плотность генеративных особей FerulalipskyiKorovin из общего числа растений составляет 25\%, вегетативных - $40 \%$, ювенильных - 20\%, а сенильных - $15 \%$. Ювенильные особи в основном встречаются в маленьких расщелинах валунов, что сохраняет их от поедания скотом. Также нами было замечено преждевременное высыхание листьев некоторых молодых растений, что является результатом заболевания.

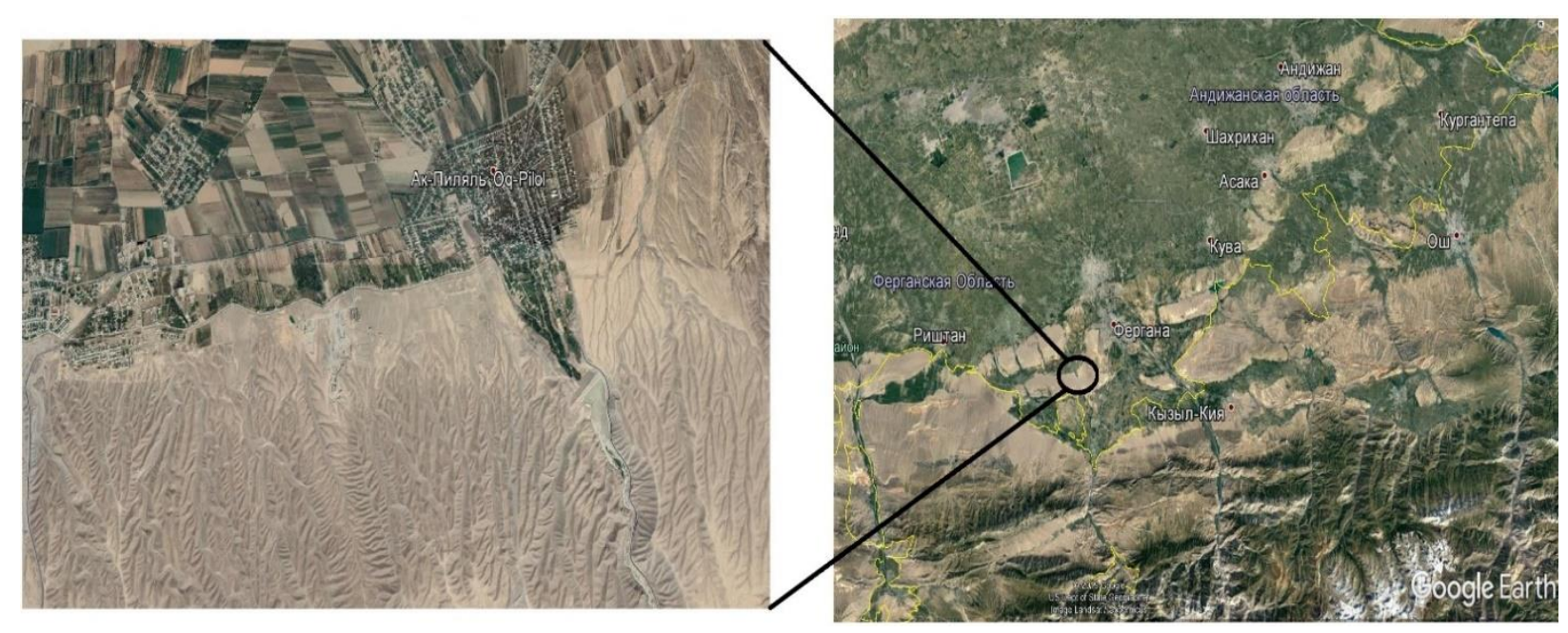

2-рисунок. Ферганский район, село Окбилол.

Название места: Ферганская область, Ферганский район, село Дамколь, 40¹9'27.77"N, 7148'54.1"Е (3-рисунок).

Популяция расположена на восточной стороне склона крутизной $35^{\circ}$, занимая общий участок площадью $20000 \mathrm{~m}^{2}$ на высоте 615-630 м над уровнем моря. Травянистый покров популяции развит умеренно слабо, с выраженной трехъярусной структурой. Травостой в видовом отношении умеренный с общим проективным покрытием 30-40\%. Первый ярус (более 60 см) представлен кустарником AmmodendronconollyiBoiss. Второй ярус (25-45 см) представлен EchinopsknorringianusIljin.,
PerovskiavirgateKudr., Scandixpecten-VenerisL., Trichodesmaincanum (Bunge) A.DC., Haplophyllumalberti-regeliiKorovin,

Meniocuslinifolius(StephanexWilld.) DC.. Третий ярус (10-20 см) образован CapparisspinozaL., MarrubiumanisodonK.Koch.,

LamioumamplexicauleL., Strigosellatrichocarpa (BoissetBunge) Botsch., Minuartiameyerii (Boiss.) Bornm., Noneacaspica (Willd.) G.Don.. Плотность популяции 4.5 экз $/ \mathrm{M}^{2}$. Плотность генеративных особейFerulaLipskyiKorovinиз общего числа растений составляет 35\%, вегетативных - 30\%, ювенильных - $15 \%$, а сенильных $-20 \%$. 


\begin{tabular}{|c|c|c|c|c|c|c|}
\hline \multirow{4}{*}{ Impact Factor: } & ISRA (India) & $=4.971$ & SIS (USA) & $=0.912$ & ICV (Poland) & $=6.630$ \\
\hline & ISI (Dubai, UAE & $=0.829$ & РИНЦ (Russia & $=0.126$ & PIF (India) & $=1.940$ \\
\hline & GIF (Australia) & $=0.564$ & ESJI (KZ) & $=8.716$ & IBI (India) & $=4.260$ \\
\hline & JIF & $=1.500$ & SJIF (Morocec & $=5.667$ & OAJI (USA) & $=0.350$ \\
\hline
\end{tabular}

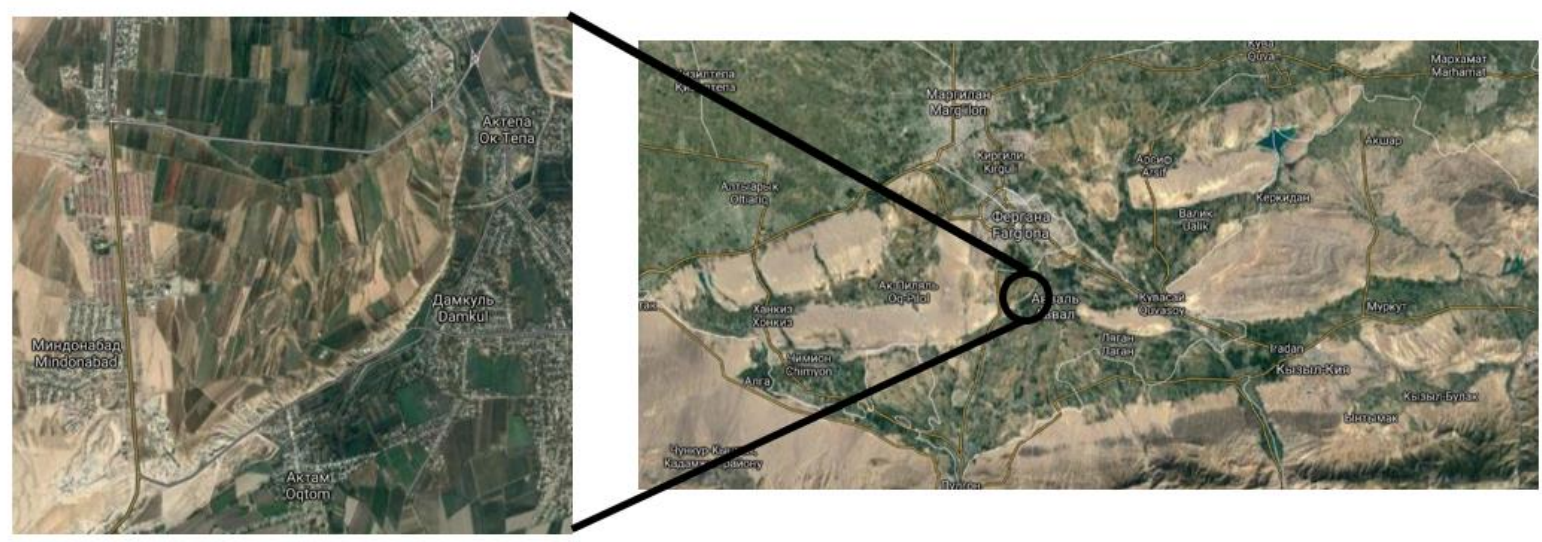

3-рисунок. Ферганский район, село Дамкол.

На всех исследованных популяциях в роли эдификатора выступает FerulaLipskyiKorovin, на долю которых в покрытии приходится 75\%. В конце февраля весьма красочный аспект создает FerulaLipskyiKorovin.
FerulaLipskyiKorovin по площади распределен рассеянно, в основном однопобеговыми, и очень редко двупобеговыми особями.

Таблица 1. Сравнение морфометрических параметров трех популяций FerulalipskyiKorov.

\begin{tabular}{|c|c|c|c|c|c|c|}
\hline \multirow{2}{*}{$\begin{array}{l}\text { № попу- } \\
\text { ляции }\end{array}$} & \multicolumn{6}{|c|}{ Средние значения морфометрических параметров } \\
\hline & $\mathrm{H}$ & $\mathrm{d}$ & $\mathrm{Ll}$ & $\mathrm{S} 1$ & $\mathrm{Nl}$ & $\mathrm{Li}$ \\
\hline П1 & $\begin{array}{ll}62,25 \\
\pm 4,123 \\
\end{array}$ & $1,29 \pm 0,214$ & $34,25 \pm 2,774$ & $36,0 \pm 4,13$ & $\begin{array}{l}7,0 \\
\pm 0,24\end{array}$ & $42,3 \pm 0,24$ \\
\hline П2 & $\begin{array}{l}51,8 \\
\pm 2,25\end{array}$ & $1,18 \pm 0,09$ & $30,0 \pm 2,04$ & $30,0 \pm 2,19$ & $\begin{array}{l}6,8 \\
\pm 0,34\end{array}$ & $36,93 \pm 1,78$ \\
\hline П3 & $\begin{array}{l}59,15 \\
\pm 5,123\end{array}$ & $1,18 \pm 0,024$ & $32,1 \pm 2,54$ & $32,6 \pm 2,66$ & $\begin{array}{l}6,9 \\
\pm 0,37\end{array}$ & $40,9 \pm 1,08$ \\
\hline
\end{tabular}

В таблице 1. приведены сравнения средних значений морфометрических параметров трех популяций FerulalipskyiKorovin. Мы обнаружили, что Окбилолская популяция, расположенная около активной автомагистрали Окбилол-Вадиль, а также на 100 метров выше чем Чимионская популяция, по ряду морфометрических параметров сильно уступает Дамколской популяции. Широта изменчивости Окбилолской популяции также намного ниже чем у Чимионской популяции.

\section{Выводы}

В данной статье, были обобщены изучение эндемических, редких и малораспространённых в ареале, а также занесённых в Красную Книгу Республики Узбекистан видов, их защита и принятие мер и мероприятий по их сохранению и защите, оценка текущего положения популяций, оценка влияния биотических, абиотических и антропогенных факторов на популяцию видов, научное обоснование адаптации влияния внешних факторов. Отсутствие точных данных о флоре Ферганской долины можно увидеть в том, что большая часть исследований посвящена растительному покрову. Ферганская долина имеет флору, эндемичный статус, малораспространённый ареал, с учётом воздействия роста населения, выпаса скота и других техногенных факторов. Это также показывает, что необходимы целенаправленные исследования видов, занесённых в Красную Книгу Республики Узбекистан. Из них мы только провели исследование на FerulalipskyiKorovin, и в нашей будущей работе мы продолжим изучать виды, внесённые в Красную Книгу Республики Узбекистан.

Исследованная популяция является эндемической для Ферганской долины, а две горные цепи в горной Центральной Азии связывают флору. Были изучены существующие популяции этого вида в районах,где преобладают антропогенные факторы (возделывание земель и чрезмерный выпас скота). Пока ещё недостаточно данных, основанных на точном анализе химического состава вида, текущего состояния популяции и общего диапазона распространения.

Анализируя результаты наших исследований, следует отметить, что жизненное состояние FerulalipskyiKorovin в трех популяциях 


\begin{tabular}{|c|c|c|c|c|c|c|}
\hline \multirow{4}{*}{ Impact Factor: } & ISRA (India) & $=4.971$ & SIS (USA) & $=0.912$ & ICV (Poland) & $=6.630$ \\
\hline & ISI (Dubai, UAE & $=0.829$ & РИНЦ (Russia & $=0.126$ & PIF (India) & $=1.940$ \\
\hline & GIF (Australia) & $=0.564$ & ESJI (KZ) & $=8.716$ & IBI (India) & $=4.260$ \\
\hline & JIF & $=1.500$ & SJIF (Morocec & $=5.667$ & OAJI (USA) & $=0.350$ \\
\hline
\end{tabular}

неодинаковое. Особое беспокойство вызывают Окбилолская и Чимионскаяпопуляции. Обнаруженные нами популяции произрастают на склонах, находящихся под углом 30-35, которые подвержены сильной эрозии дождевыми ливнями, в результате которых смывается основная масса почвы и остаются только камни, которые образуют неблагоприятную среду для произрастания семян.Также среди естественных факторов, негативно влияющих на развитие взрослых растений, следует отметить резкое уменьшение количества осадков по сезонам, быстрая смена климата, приводящая к гибели молодых заростков. Основными антропогенными факторами, ведущими к уменьшению числа растений данного вида, являютсяочень близкое расположениек населенному пункту, периоды интенсивный выпас скотав ранне весенние,на территориях произрастания популяций, строительство автомагистрали Окбилол-Вадиль. Сильное воздействие на состояние Дамкольской популяции оказывает использование близлежащих к ареалу популяции территорий, как место для хранения хозяйственных и бытовых отходов. На состояние Чимионской популяции сильное влияние оказывает нахождение оздоровительного комплекса «Зилол», который создает сильную рекреативную нагрузку для данного ареала. Поэтому для того, чтобы сохранить популяцию FerulalipskyiKorovin необходимо взять эту территорию под контроль.

Поэтому рекомендуется проводить контроль над наблюдением за данным видом.

\section{References:}

1. Pimenov, M.G. (1983). Semejstvo zontichnyeUmbelliferae. Opredelitel' rastenij Srednej Azii. (pp.167-316). Tashkent:Fan, T.7.

2. (n.d.). International Plants Names Index. Retrieved from www.ipni.org

3. (n.d.). The Plant List. Retrieved from www.theplantname.com

4. Brummit, R.K., \& Powell, C.E. (1992). Authors of Plant Names", 1992, is a print database of accepted standardized abbreviations used for citing the author who validly published the name of a taxon.

5. (2011). ESRI 2011. ArcGIS Desktop: Release 10. Redlands, CA: Environmental Systems Research Institute.

6. Shherbakov, A.V., \& Majorov, S.R. (2006). Polevoe izuchenie flory i gerbarizacija. (p.84). Moscow: Izd. kaf. vysshih rastenij biol. f-ta Mosk. un-ta.

7. Korovin, E.P. (1952). Semejstvo zontichnyeUmbelliferae. Flora SSSR.M.L., 1952(4) T.17, pp.1-314

8. Korovin, E.P. (1959). Umbelliferae Zontichnye. Flora Uzbekistana. (pp.257-470). Tashkent: AN UzSSR, T. IV.

9. Korovin, E.P. (1947). Illjustrirovannaja monografija roda Ferula (Tourn) L... (p.91). Izd. AN UZ SSSR, Toshkent.

10. Rabotnov, T.A. (1950). Zhiznennye cikly mnogoletnih travjanistyh rastenij $\mathrm{v}$ lugovyh cenozah /Tr. Botan. in-ta AN SSSR. - M -L., ser. 3, vyp. 6, pp. 5-204.

11. Zlobin, Ju.A., Skljar, V.G., \& Klimenko. A. A. (2013). Populjacii redkih vidov rastenij: teoreticheskie osnovy $i$ metodika izuchenija : monografija . (p.439). Sumy : Universitetskaja Tit.

12. Zlobin, Ju. A. (1989). Principy $i$ metody izuchenija cenoticheskih populjacij rastenij. (p.146). Kazan': Izd-vo Kazanskogo gosudarstvennogo universiteta.

13. Batoshov, A.R., \& Kadyrov, R.U. (2012). O novyh vidah roda Ferula L. (Apiaceae) dlja flory Uzbekistana. Uzbekskij biologicheskij zhurnal. - Spec. vypusk, Tashkent: Fan, pp. 11-13.

14. Abd El-Razek M.H., et al. (2001). Sesquiterpene coumarins from the Roots of Ferula Asafetida. Phytochem. 58: 1289-1295.

15. Kojima, K., et al. (2000). Sesquiterpenoid Derivatives from Ferula Feruloides IV. Chem Pharm Bull., 48: 353-356.

16. Gonzalez, A.G., \& Barrera, J.B. (1995). Chemistry and the Sources of Mono and Bicyclic Sesquiterpenes from Ferula Species. Progress Chem Org Nat Prod., 64: 1-92.

17. Abd El-Razek, M.H., Ohta, S., \& Hirata, T. (2003). Terpenoid coumarins of the Genus Ferula. Heterocycles, 60: 689-716.

18. Sahebkar, A., \& Iranshahi, M. (2010). Biological Activities of Essential Oils from the Genus Ferula (Apiaceae). Asian Biomed, 4(6): 835847.

19. Downie, S.R., et al. (2000). Molecular Systematics of Old World Apioideae (Apiaceae): Relationships among Some Members of Tribe Peucedaneae sensu lato, the Placement of Several Island Endemic Species, and Resolution within the Apioidsuperclade. Canad J Bot., 78: 506-528. 


\begin{tabular}{|c|c|c|c|c|c|c|}
\hline \multirow{4}{*}{ Impact Factor: } & ISRA (India) & $=4.971$ & SIS (USA) & $=0.912$ & ICV (Poland) & $=6.630$ \\
\hline & ISI (Dubai, UAE & $=0.829$ & РИНЦ (Russia) & $=0.126$ & PIF (India) & $=1.940$ \\
\hline & GIF (Australia) & $=0.564$ & ESJI (KZ) & $=8.716$ & IBI (India) & $=4.260$ \\
\hline & JIF & $=1.500$ & SJIF (Morocco) & $=5.667$ & OAJI (USA) & $=0.350$ \\
\hline
\end{tabular}

20. Lee, B.Y., \& Downie, S.R. (2000). Phylogenetic Analysis of cpDNA Restriction Sites and rps16 Intron Sequences Reveals Relationships among Apiaceae Tribes Caucalideae, Scandiceae and Related Taxa. Pl Syst Evol., 221: 35-60.

21. Zhou, J., et al. (2009). Towards a More Robust Molecular Phylogeny of Chinese Apiaceae Subfamily Apioideae: Additional Evidence from nrDNA ITS and cpDNA Intron (rpl16 and rps16) Sequences. Mol Phyl Evol., 53: 56-68.

22. Zhou, J., et al. (2008). A Molecular Phylogeny of Chinese Apiaceae Subfamily Apioideae
Inferred from Nuclear Ribosomal DNA Internal Transcribed Spacer Sequences. Taxon, 57: 402416.

23. Kurzyna-Młynik, R., et al. (2008). Phylogenetic Position of the Genus Ferula (Apiaceae) and its Placement in Tribe Scandiceae as Inferred from nrDNA ITS Sequence Variation. Pl Syst Evol., 274: 47-66.

24. Kamelin, R.V. (1973). Floristicheskij analiz estestvennoj flory gornoj Srednej-Azii. (p.354). Leningrad: Nauka. 